\title{
SOME MORPHOLOGICAL CHARACTERISTICS \\ OF THE WATER SCORPION NEPA CINEREA (HETEROPTERA: NEPOMORPHA) ARE ASSOCIATED WITH HABITAT TYPE*
}

\author{
Gábor Bakonyi ${ }^{1 *}$, Eszter Peták ${ }^{1}$, Tibor Erôs $^{2}$ and Péter Sály ${ }^{2}$ \\ ${ }^{1}$ Department of Zoology and Animal Ecology, Szent István University \\ H-2100 Gödöllö, Páter K. u. 1, Hungary \\ ${ }^{*}$ E-mail: bakonyi.gabor@mkk.szie.hu \\ ${ }^{2}$ Department of Hydrozoology, Balaton Limnological Institute \\ MTA Centre for Ecological Research, H-8237 Tihany, Hungary \\ E-mails: eros.tibor@okologia.mta.hu, saly.peter@okologia.mta.hu
}

Morphological variation can enable species to successfully survive and reproduce in distinct habitats. Water scorpion (Nepa cinerea Linnaeus, 1758) occurs in different aquatic habitats from lentic to lotic conditions. We examined the morphology of $N$. cinerea collected from a diverse array of habitat types (creeks, canals, ponds) in order to explore possible morphological adaptations to the habitat. We addressed the following specific questions: (i) is there any morphological differences between specimens collected from distinct habitats, and if so, (ii) is it possible to relate differences in morphology of the N. cinerea to characteristics of the habitat structure? Altogether 121 individuals (69 males and 52 females) were sampled from 17 sampling sites in the catchment area of Lake Balaton (Hungary). 54 body parameters were determined on all individuals. According to five habitat parameters (bottom quality, current velocity of the water, water depth, submerse plant density, shading) sampling sites were clustered into two distinct groups. Submerse plant density proved to be the most important discriminating factor between the two groups. The morphology of the $N$. cinerea (both males and females) sampled from the two contrasting habitat types were different. No relationship was found between geographical position of the habitat type and body morphology of $N$. cinerea. Leg morphology, especially claws on the third leg and some body shape parameters showed relationships with habitat characteristics. These morphological variations, which may be the result of phenotypic plasticity, could contribute to an opportunistic habitat choice of the species.

Key words: Nepidae, phenotypic plasticity, submerse vegetation, leg morphology, ordination.

\section{INTRODUCTION}

Relationship between body morphology and habitat is a key factor in understanding the mechanisms of evolution (WEST-EBERHARD 1989, ViA et al. 1995, Agrawal 2001). In the case of water insects some morphological characters as e.g. body size and shape, leg arrangement of populations from various taxa are strongly related to environmental factors as hydraulic conditions,

*This paper dedicated to Prof. László Papp the reknown Diptera taxonomist and insect ecologist former Editor-in-Chief of the Acta Zoologica Academiae Scientiarum Hungaricae. 
substrate of the bottom or vegetation density (Dahl \& Peckarsky 2002, ORLOFSKE \& BAIRD 2014). Benthic organisms are exposed frequently to flowing water. A morphological adaptation of body shape is a way in order to reduce hydraulic stress (STATZNER \& Holm 1982). For example, lack of protected microhabitat had strong effect on stonefly phenotype. Franken et al. (2008) showed reduced body size in the case of the stonefly Nemoura cinerea (Retzius, 1783) (Plecoptera: Nemouridae) in sandy bottom where refugia were absent. The fan morphology of the blackfly Simulium lundstromi (Enderlein, 1921) (Diptera: Simuliidae) larvae was found to be adapted to different current velocities in order to enable sufficient feeding at different flow regimes (ZHANG \& MalmQvist 1997, Malmovist et al. 1999).

Quantitative studies on the intraspecific phenotypic plasticity of some Nepomorpha species in relation to various habitat parameters have also been performed in some cases. Sites et al. (1996) found shape differences among three Ambrysus mormon Montandon, 1909 (Naucoridae) populations collected from sites with notably different mean average temperatures. Phenotypic plasticity or modulated ontogeny was suggested as source of intraspecific morphological differences. Morphological adaptation of the wings and legs in relation to the habitat was examined in the case of the corixid Arctocorisa carinata (Sahlberg, 1819) (Corixidae) by JANSSON and PAJUnEN (1978). With the aid of multivariate methods it was possible to distinguish morphologically related population groups. Claws of the second leg were found the most important grouping character. The function of these claws is grasping to the bottom. Intraspecific adaptation to the hard bottom was manifested in short claw.

N. cinerea L., 1758 is a common aquatic insect, extensively distributed and frequent in the Palaearctic region (PolHemus 1995). Its population density can be high in a wide variety of habitats. Field studies in Norway suggest that this species prefer vegetation rich running waters (e.g. rivers) where sediment is dygyttja or clay/gyttja (Coulianos et al. 2008). Lock et al. (2013) found most specimens in brooks in a country wide sampling program in Belgium. N. cinerea was found in moderate density in the reed area of the clear water lakes by VAN DE MeutTer et al. (2005). Small water bodies with varying conductivity, depth and macrophyte coverage were primer habitat for N. cinerea in Spain (CARBONELL et al. 2011). According to TAMANINI (1979) this species lives near the banks of slow flowing streams, springs, canals and wetlands with aquatic plants and plant debris. In Italy $N$. cinerea is present also in rivers, and in waters without or with scarce vegetation (F. Cianferoni, pers. comm.). Results of GARCíA-AviLÉs et al. (1996) and HufNagel et al. (1999) showed that N. cinerea occurs frequently in small streams with little current and where the vegetation is abundant. Since the species occurs among diverse environmental conditions it may provide an ideal model to examine the morphological response of aquatic insects to environmental heterogeneity. However, to our knowledge no study to date examined in detail the phenotypical plasticity of $N$ cinerea in response to habitat conditions. 
We asked two questions as follows: (i) is there any morphological differences between specimens collected from distinct habitats, and if so, (ii) is it possible to relate differences in morphology of the $N$. cinerea to habitat structure characteristics?

\section{MATERIAL AND METHODS}

The samples were taken in small aquatic habitats (e.g. creeks, canals, ponds) in the catchment area of Lake Balaton (Fig. 1) in August 2012. Nepa cinerea Linnaeus, 1758 individuals were collected with long handled O-frame water net in a diameter of $25 \mathrm{~cm}$ and mesh size $0.5 \mathrm{~mm}$. Altogether 22 sampling sites were examined for $N$ cinerea of which at least one specimen was found in 17 sites (Table 1). Altogether 121 individuals (69 males and 52 females) were sampled. All specimens were stored in $98 \%$ ethanol in separate jars. Morphological measurements were performed about one year after sampling. Specimens are deposited at the Department of Zoology and Animal Ecology, Szent István University, Gödöllő. Some sampling sites were selected close to each other, others in more distance in order to eliminate geographical effects as much as possible. Largest distance between

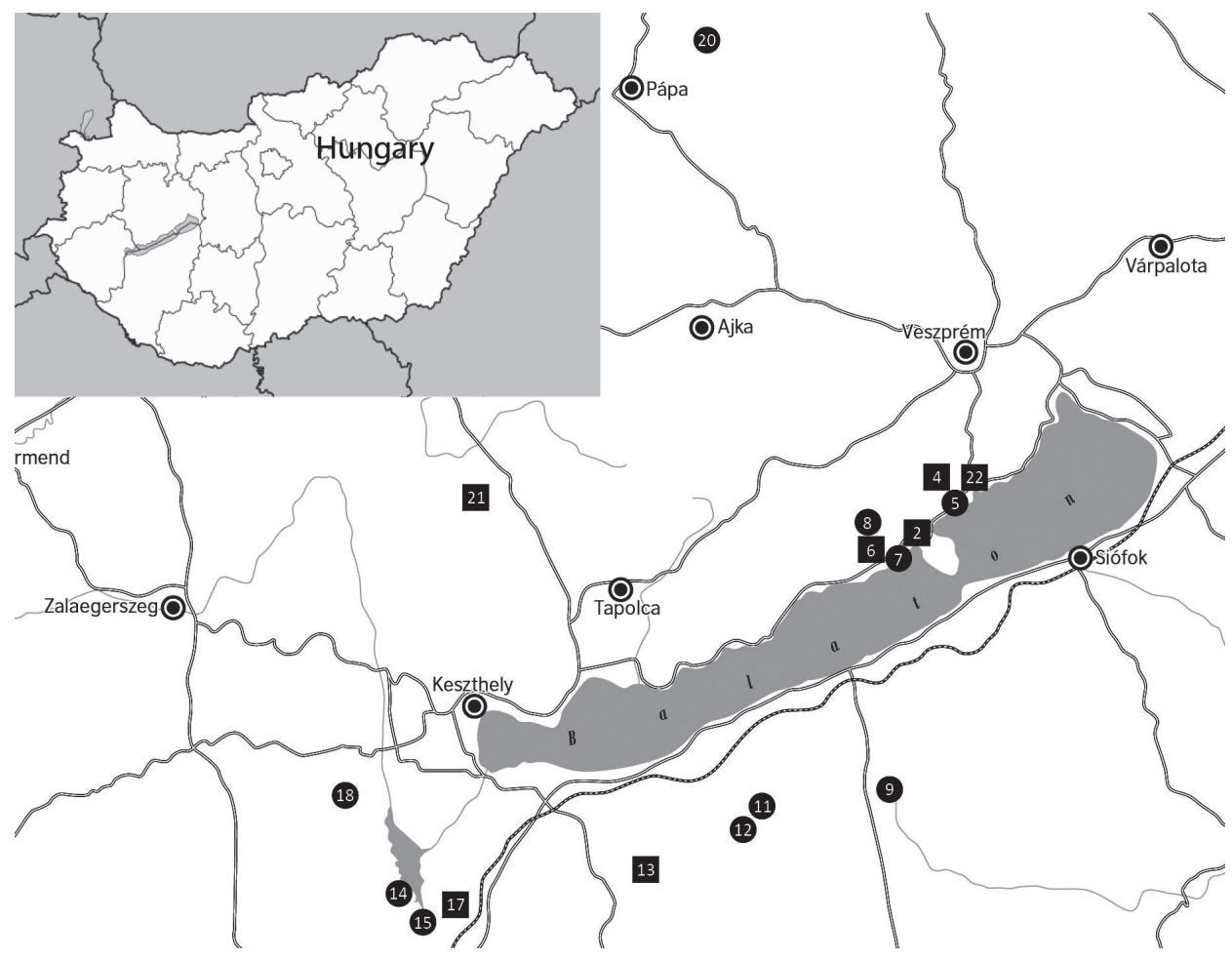

Fig. 1. Location of the sampling sites in the catchment of Lake Balaton, Hungary. Square: sampling sites are belonging to the habitat group A, Circle: sampling sites are belonging to the habitat group B. Sampling sites without $N$. cinerea are not indicated. 


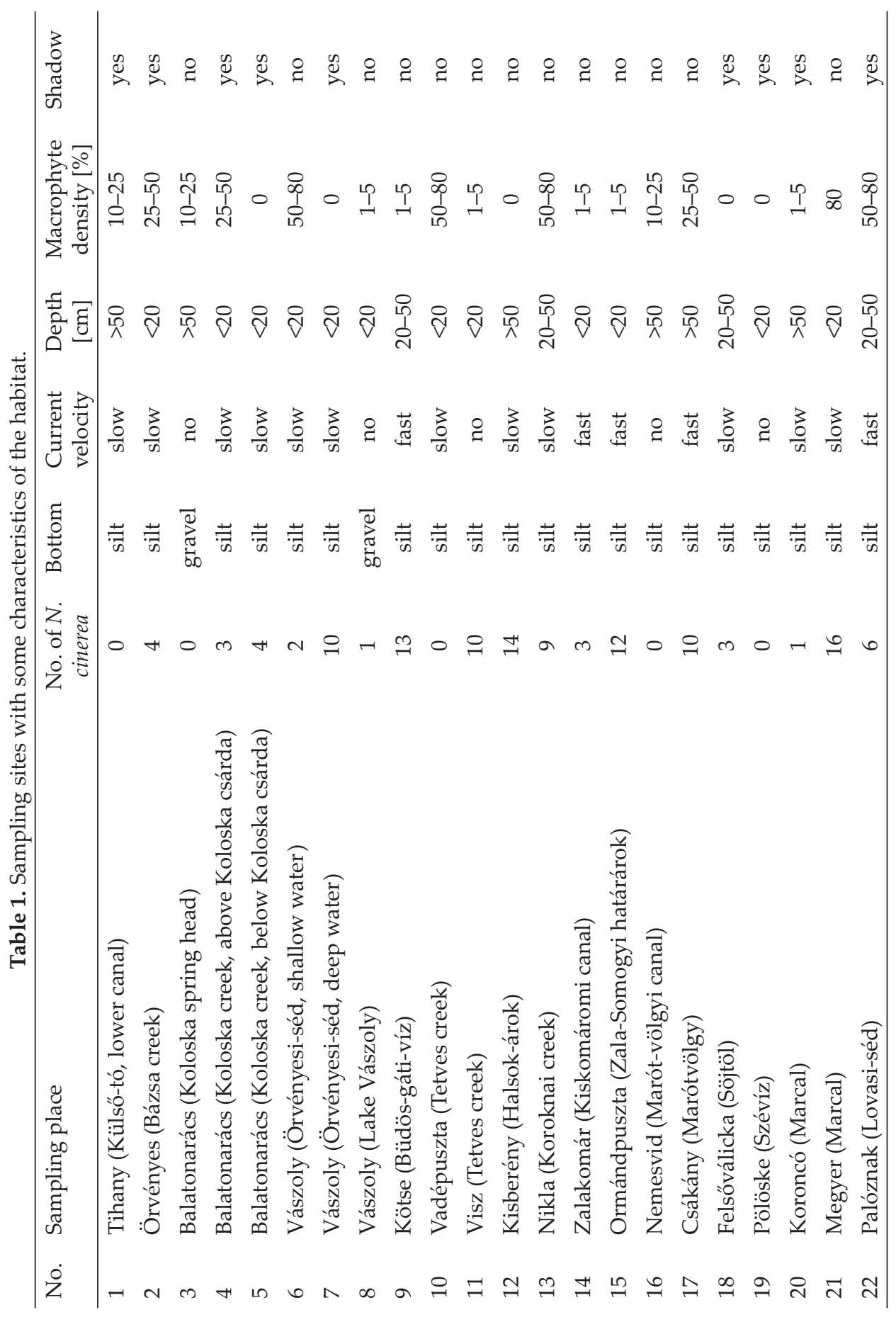


two sampling sites was almost $120 \mathrm{~km}$ (Fig. 1). Five habitat parameters were recorded at all sampling sites, as follows: (1) bottom quality (silt or gravel), (2) current velocity of the water (standing water $<0.1 \mathrm{~m} \mathrm{~s}^{-1}$; slow, $0.1-0.5 \mathrm{~m} \mathrm{~s}^{-1}$; strong, $1.0-2.0 \mathrm{~m} \mathrm{~s}^{-1}$ according to Nosek et al. (2007), (3) water depth $(<20 \mathrm{~cm}, 20-50 \mathrm{~cm},>50 \mathrm{~cm}),(4)$ submerse plant density (evaluated as plant cover per $\mathrm{m}^{2}, 0 \%, 1-10 \%, 10-25 \%, 25-50 \%, 50-80 \%,>80 \%$, according to Nosek et al. (2007) and (5) area shaded by vegetation (yes, no).

Body parameters were $\ln (x+1)$ transformed in order to improve normality of the distribution of the data. Raw data of the body parameters were compared between habitat types with two-sampled t-tests (Microsoft Excel) for both sexes separately.

To examine the association between habitat types and N. cinerea morphology, first, the habitat parameters of the sampling sites were clustered (Euclidean distance, complete linkage algorithm) to find groupings (i.e. habitat types) among them. After that, a linear discriminant analysis (LDA) was performed to reveal which morphological features differ according to the habitat types. Cluster analysis and LDA were conducted in the R environment (R CoRe TеAм 2013). We do not interpret loadings in the structure matrix unless they are 0.2 or higher.

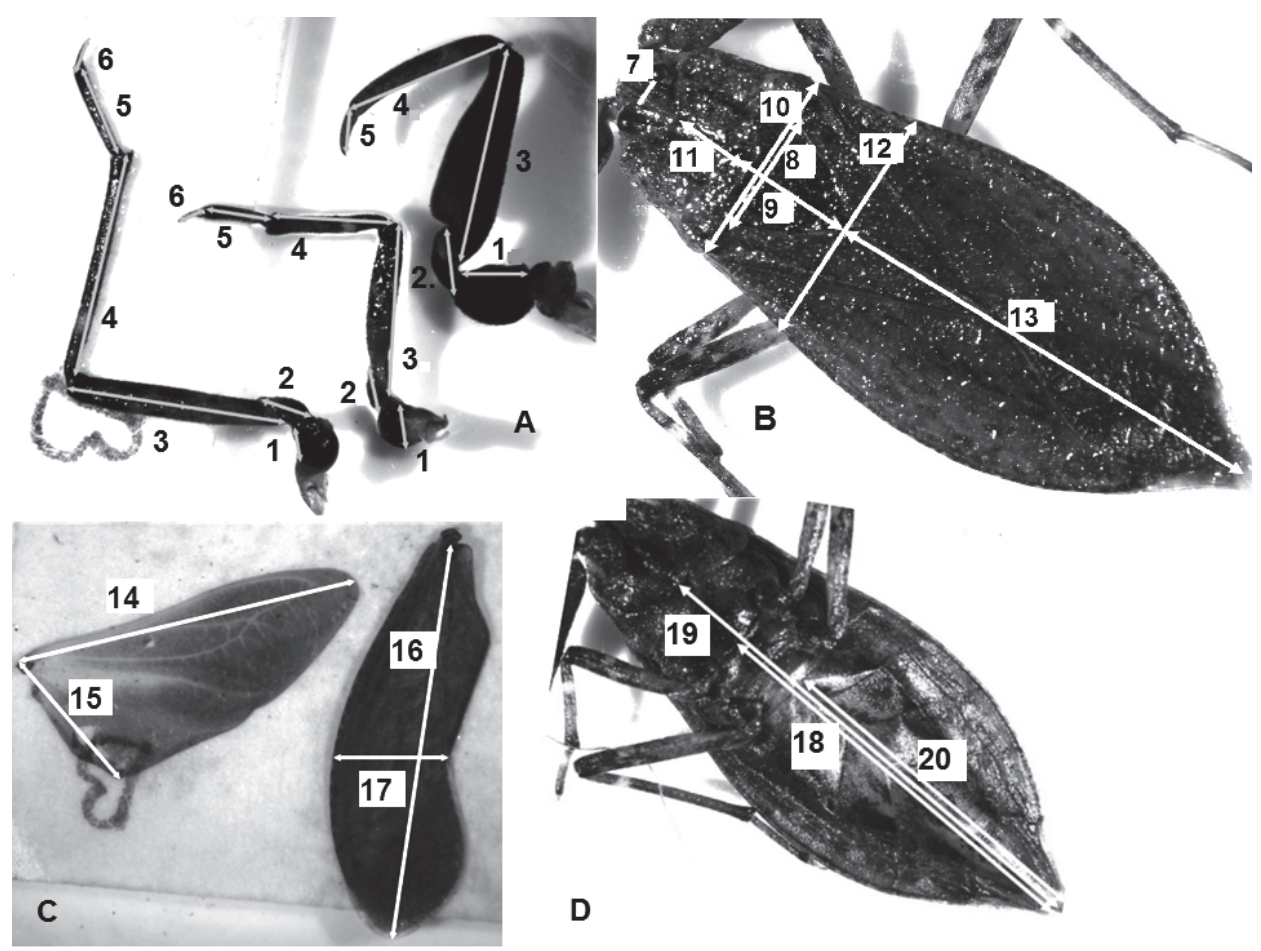

Fig. 2. Position of the measurements. A: lengths of the coxa (1), trochanter (2), femur (3), tibia (4), tarsus (5) and claw (6) on all legs (forelegs do not bear claws), B: distance between the eyes (7), width and length of the scutellum (8-9) and prothorax (10 and 11), width of the mesothorax (12), body length from the end of the scutellum to the anal siphon (13), C: length and width of the first (16-17) and second (14-15) pair of wings, D: distance of the frontal edge of the pro-(19), meso-(18) and metathorax (20) from the anal siphon basis, (anal siphon is not showed). 
Landmark based methodology was used for the geometric morphometric analysis. Ten landmarks were defined on the photos made from dorsal view. Landmarks were digitalised using the tipDig 2.17 software (Rohlf 2013). The MorphoJ, version 1.06b program package was used for further analyses (KLingenberg 2011). Procrustes fit was performed first. Thereafter covariance matrix was generated and canonical variate analysis (CVA) was performed to test for the existence of differences in body shape between habitats. Sexes were handled separately. Only those sampling sites were included, where at least 5 individuals were collected. Six sites for males and three for females fit this requirement.

\section{RESULTS}

\section{Habitats}

Sampling sites clustered into two main groups (Mann-Whitney U-test, $\mathrm{z}$-score $=-3.4, p<0.001$ ) (Fig. 3). Seven sampling sites belonged to the group A. This group of habitats could be characterized by rich submerse vegetation. The group B contained ten sampling sites. The main characteristics of these habitats is that they are poor in submerse vegetation. Other habitat parameters (bottom quality, current velocity of the water, water depth and area shaded by vegetation) did not differ considerably between the two habitat groups.

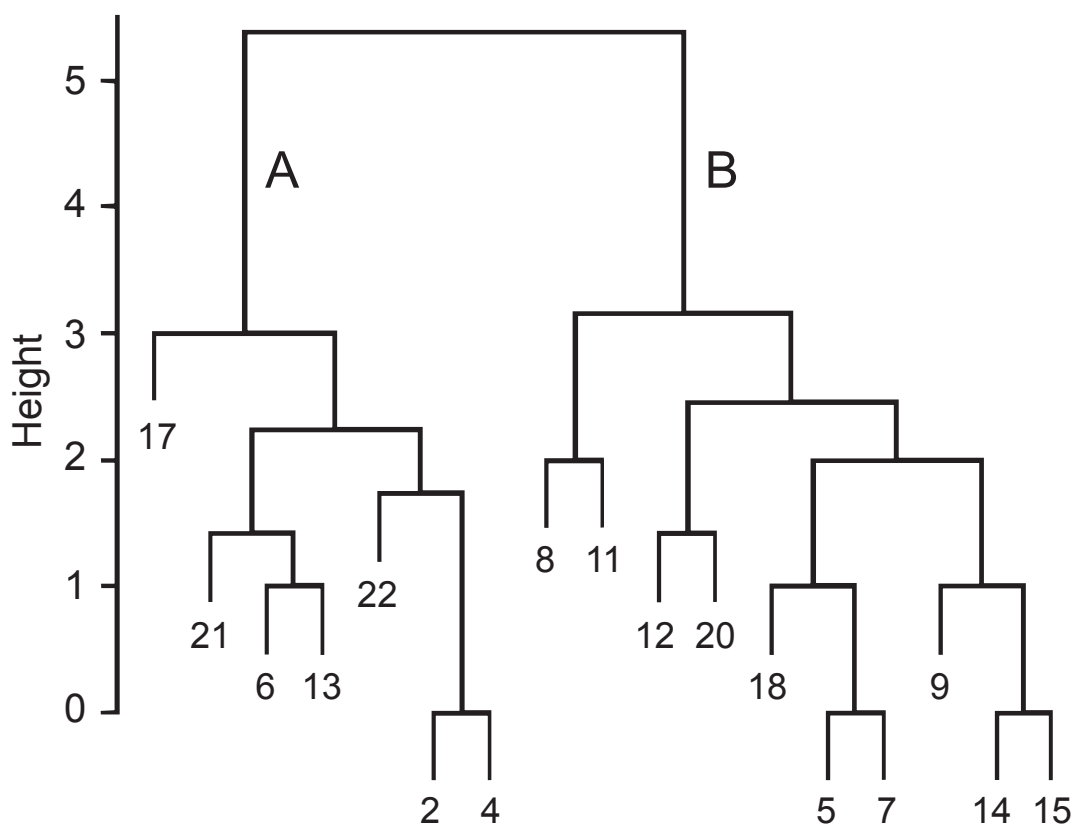

Fig. 3. Two habitat group clusters of the sampling sites. Numbers represent different sampling sites according to the Table 1. A: habitats rich in submerse vegetation, B: habitats poor in vegetation. 
The two groups were not related to the geographical position or latitude of the sampling sites. Sampling sites No. 15 and No. 17 were located relatively close to each other in the field, but differences in habitat characteristics were the greatest (Fig. 3). On the other side, the two furthermost sampling sites (No. 15 and No. 20) belonged to the same cluster.

\section{Morphological differences between sexes}

The body length of the male and female $N$. cinerea individuals is considerably different. Average body length \pm SE in millimetre of the male $15.7 \pm 0.9$ and that of female 18.1 \pm 1.3 was different $(t=-12.2, p<0.001)$. Significant difference between male and female body length suggests that sex is an important factor, if body morphology is in focus of any study. Substantial overlap in body length distribution was observed between sexes (Fig. 4). Male body length was similar, but that of female was different, if the same sex, belonging to the two habitat groups were compared $(p=0.24$ and $p=0.02$ for male and female, respectively).

\section{Association between body morphology and habitat types}

Results of the linear discriminant analysis showed that the morphology of the $N$. cinerea (both males and females) were different according to their habitats (Figs $5 \& 6$ ). The difference is more expressed in the case of fe-

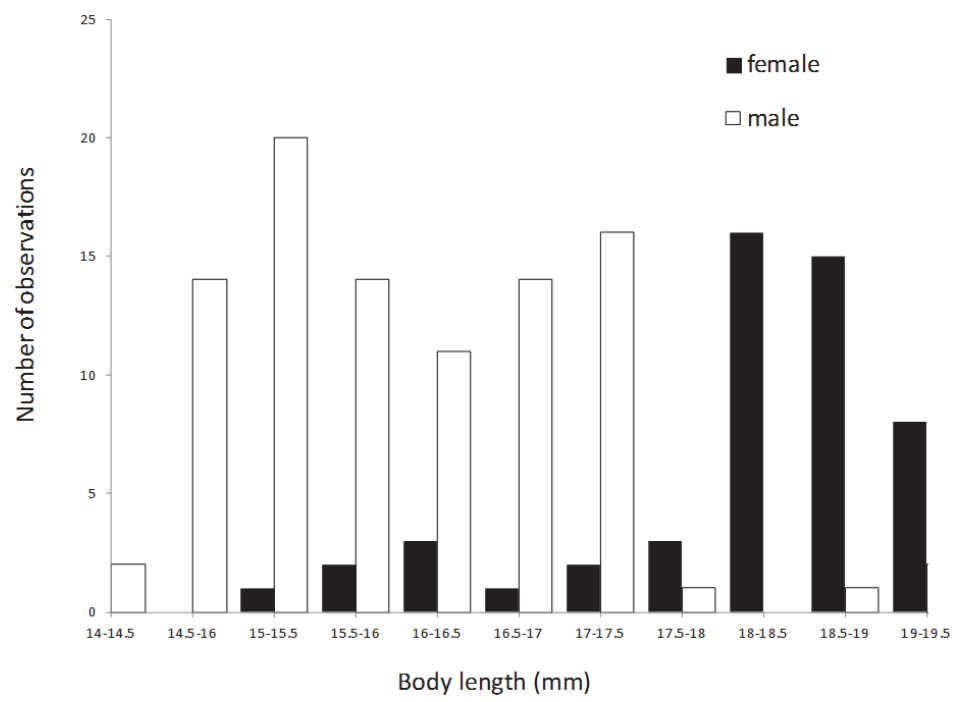

Fig 4. Body length distribution of the N. cinerea males and females. All sampled individuals are included. 


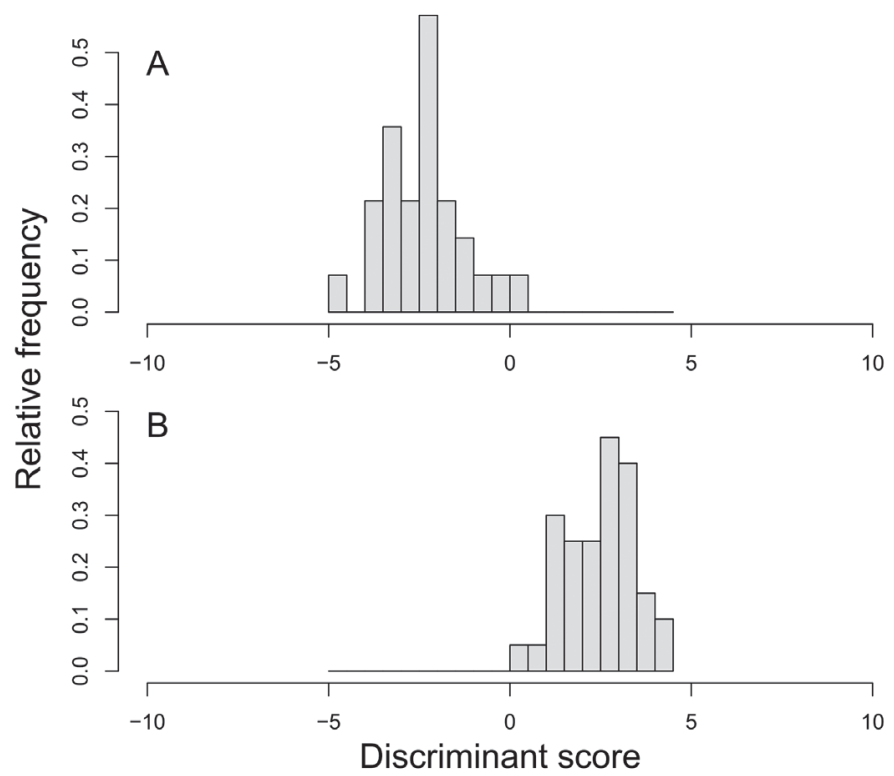

Fig. 5. Two-class linear discriminant analysis for male $N$. cinerea based on measured body parameters. Bar shows frequency distribution of the data. A: specimens belonging to habitats rich in submerse vegetation, B: specimens belonging to habitats poor in vegetation.

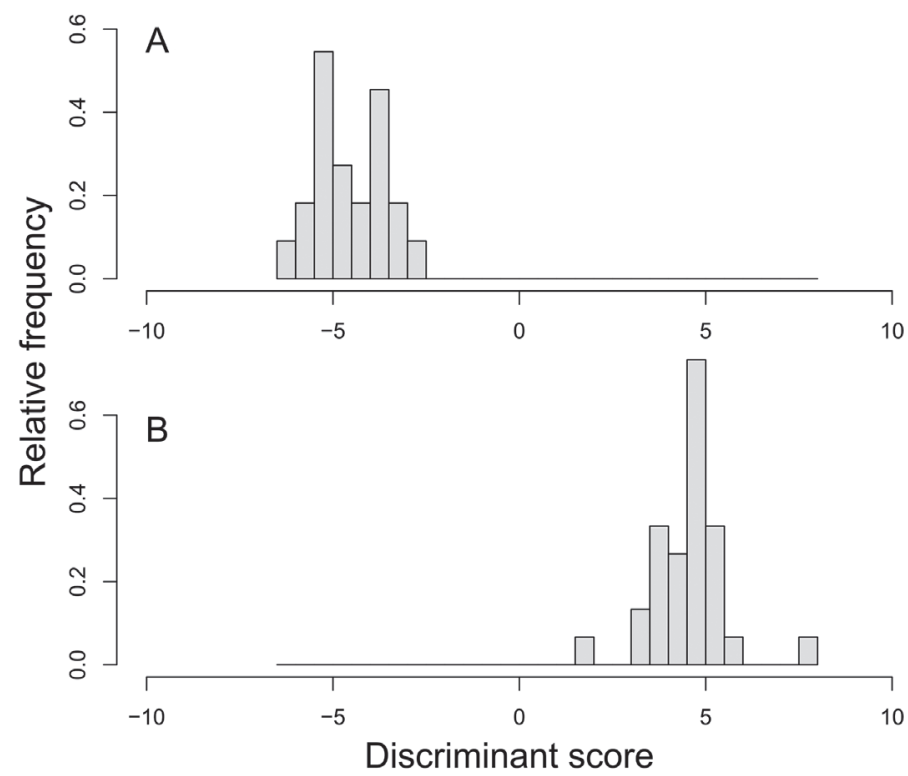

Fig. 6. Two-class linear discriminant analysis for female N. cinerea based on measured body parameters. Bar shows frequency distribution of the data. A: specimens belonging to habitats rich in submerse vegetation, B: specimens belonging to habitats poor in vegetation. 
males than males. In the case of the females the first linear discriminant (LD1) average $\pm S D$ was $-5.22 \pm 0.94$ and $3.83 \pm 1.04$ for habitat type $A$ and $B$, respectively. The difference was not so large if the data of the males is regarded. For males average $\mathrm{LD} 1 \pm \mathrm{SD}$ was $-2.85 \pm 1.06$ and $2.00 \pm 0.96$ for habitat type $\mathrm{A}$ and $\mathrm{B}$, respectively. Different body morphology was found even if the sampling sites of the $N$. cinerea were close to each other, and oppositely, morphologically similar populations were found in notably distant sampling sites.

Geometric morphology analysis strongly supports this statement. Figure 7 shows that males from sampling sites No. 15 and No. 21 are very similar to each other, although the sites in a straight line are as far as $62 \mathrm{~km}$. Oppositely, morphological differences is noteworthy even if the sampling sites are only $18 \mathrm{~km}$ from each other (sites No. 9 and No. 12) in the case of both sexes. Sites No. 11 and No. 12 are only $6 \mathrm{~km}$ distance from each other, even though male morphology was different (Figs 7 \& 8).

Searching for body parameters which are responsible for morphological differences, averages of all measured parameters were compared for specimens sampled from the habitat type A and B. In the case of the legs and wings correlation between body parameters and habitat type was accepted only, when LD1 was higher than 0.2 for both right and left appendages (symmetry of the appendages was presumed). In some cases body and habitat parameters showed good correlation at both sexes. Length of the hind leg tarsus, length of the hind leg claw, width of the pronotum and distance between eyes were these parameters (Table 2). Moreover, nine further parameters for females and three for males confirmed correlation between body morphology and habitat type (Table 2).

Comparing body parameters significant differences were found for females ( $n=7$ cases) as well as for males ( $n=9$ cases) regarding to their habitat type (Table 3). All significantly different body parameters were greater in those individuals which were found in habitat type B. This finding is not related to the sex. These result shows that individuals found in habitat type where submerse plant density is low, had higher average values at both sexes in all significantly different body parameters than those found in vegetation rich habitat type. The length of the hind leg claw is especially worthy of note. It was the only body parameter which proved to be significantly greater of the individuals from habitat type B irrespectively of sex.

Certain body parameter differences were related to the sex as well. Body length from the end of the scutellum to the anal siphon and the distance between the eyes was greater at females sampled from habitat type B. In the case of males sampled from habitat type B the tarsus of the middle leg, claws on middle and hind legs and the width of the prothorax were greater. 


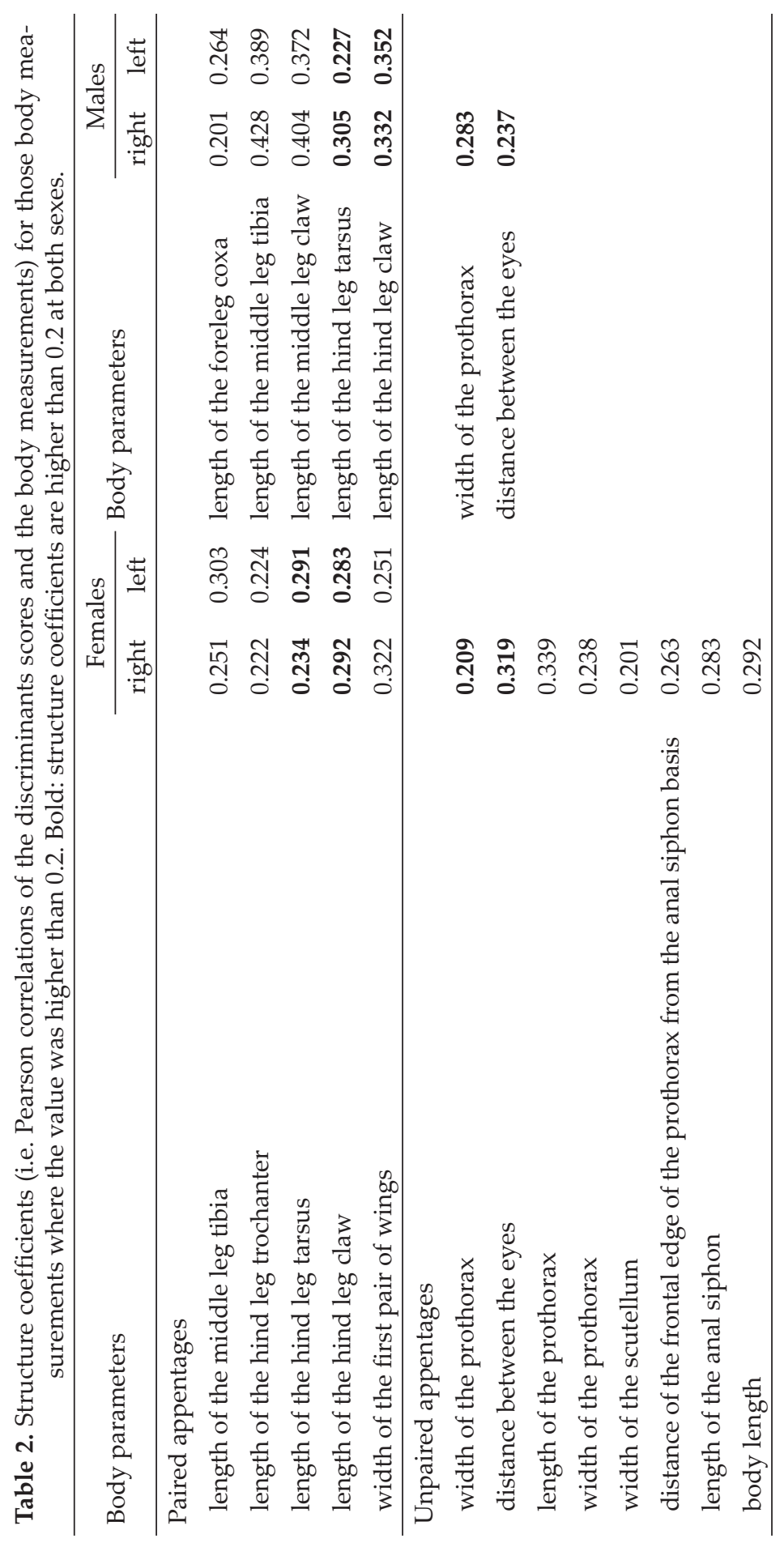




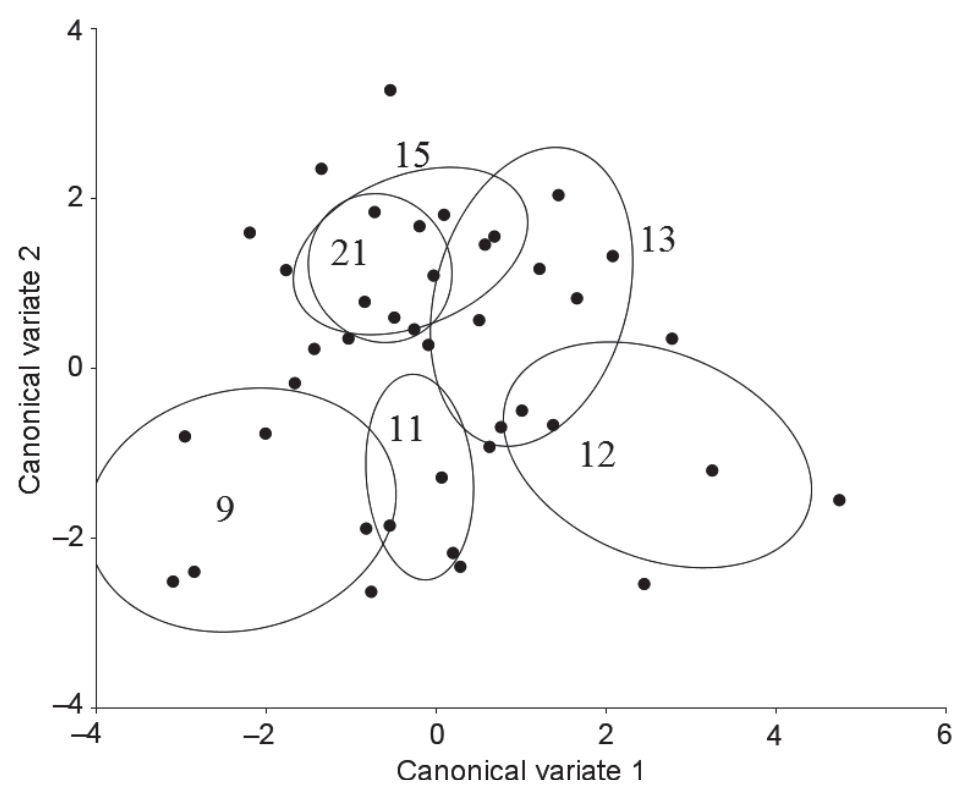

Fig. 7. Canonical variate analysis for males. Only those sampling sites were involved into the analysis where $n \geq 5$. Confidence ellipses for means are shown (probability is 0.9 ).

Numbers refers to localities in Table 1.

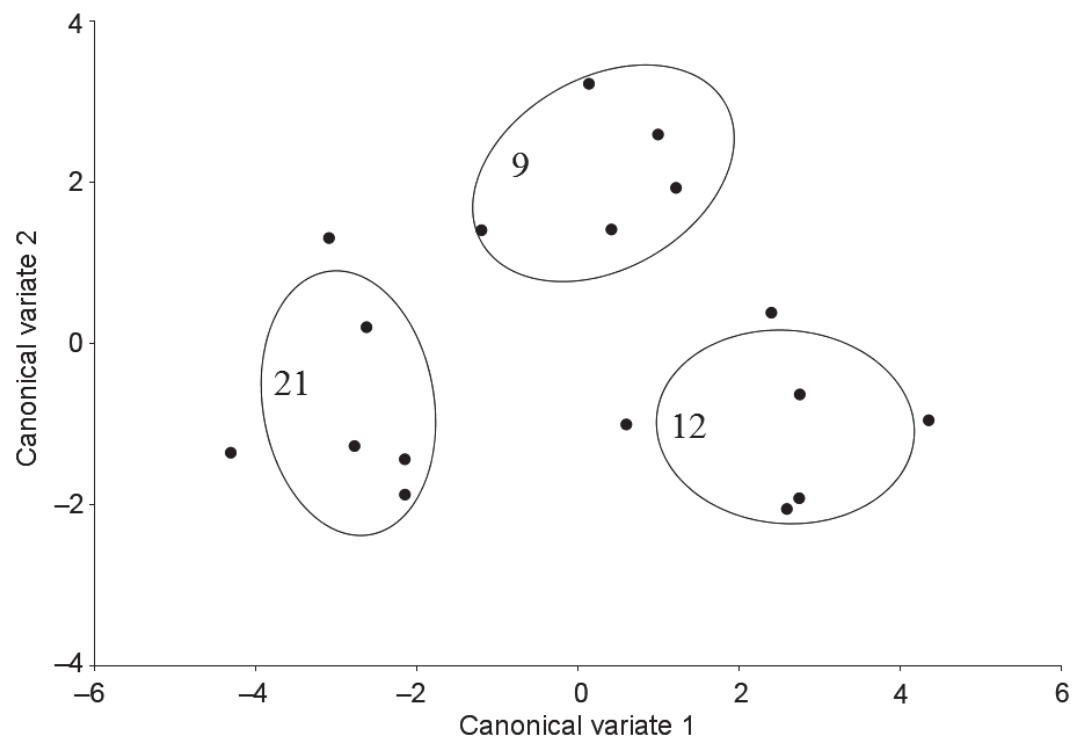

Fig. 8. Canonical variate analysis for females. Only those sampling sites were involved into the analysis where $n \geq 5$. Confidence ellipses for means are shown (probability is 0.9 ).

Numbers refers to localities in Table 1. 
Table 3. Body measurements in $\mathrm{mm}( \pm \mathrm{sd})$. Only those data are indicated where significant differences were found at least either sex. ${ }^{*} \mathrm{p}<0.05,{ }^{* *} \mathrm{p}<0.01,{ }^{* * *} \mathrm{p}<0.001$.

\begin{tabular}{lcccc}
\hline Body parameters & \multicolumn{2}{c}{ Male } & \multicolumn{2}{c}{ Female } \\
\hline & GroupA & GroupB & GroupA & GroupB \\
\hline $\begin{array}{l}\text { Middle leg (right) } \\
\text { tarsus }\end{array}$ & $1.41 \pm 0.10$ & $1.51 \pm 0.12^{* * *}$ & $1.60 \pm 0.13$ & $1.64 \pm 0.12$ \\
$\quad$ claw & $0.49 \pm 0.07$ & $0.54 \pm 0.07^{* *}$ & $0.52 \pm 0.09$ & $0.59 \pm 0.07^{* *}$ \\
Hind leg (right) & & & & \\
$\quad$ tarsus & $2.00 \pm 0.14$ & $2.09 \pm 0.14^{*}$ & $2.26 \pm 0.21$ & $2.44 \pm 0.15$ \\
$\quad$ claw & $0.55 \pm 0.07$ & $0.60 \pm 0.01^{*}$ & $0.57 \pm 0.08$ & $0.62 \pm 0.09^{*}$ \\
Foreleg (left) coxa & $1.30 \pm 0.12$ & $1.37 \pm 0.13^{*}$ & $1.44 \pm 0.13$ & $1.50 \pm 0.15$ \\
Middle leg (left) & & & & \\
$\quad$ tibia & $2.77 \pm 0.20$ & $2.78 \pm 0.20$ & $3.02 \pm 0.19$ & $3.12 \pm 0.19^{*}$ \\
$\quad$ tarsus & $1.41 \pm 0.13$ & $1.50 \pm 0.13^{* *}$ & $1.60 \pm 0.13$ & $1.65 \pm 0.14$ \\
$\quad$ claw & $0.48 \pm 0.07$ & $0.53 \pm 0.08^{* *}$ & $0.53 \pm 0.09$ & $0.55 \pm 0.07$ \\
Hind leg (left) claw & $0.55 \pm 0.08$ & $0.60 \pm 0.07^{* *}$ & $0.58 \pm 0.08$ & $0.63 \pm 0.08^{*}$ \\
Body length from the end & & & & \\
of the scutellum to the anal & $10.86 \pm 0.78$ & $10.97 \pm 0.62$ & $12.40 \pm 1.04$ & $12.96 \pm 0.59^{*}$ \\
siphon & & & & \\
Width of the prothorax & $5.05 \pm 0.35$ & $5.23 \pm 0.29^{*}$ & $5.71 \pm 0.51$ & $5.87 \pm 0.27$ \\
$\begin{array}{l}\text { Distance between the eyes } \\
\text { Width of the first wing (right) }\end{array}$ & $0.79 \pm 0.11$ & $0.84 \pm 0.11$ & $0.83 \pm 0.11$ & $0.90 \pm 0.12^{*}$ \\
\hline & $3.58 \pm 0.28$ & $3.60 \pm 0.25$ & $4.14 \pm 0.39$ & $4.34 \pm 0.23^{*}$ \\
\hline
\end{tabular}

\section{DISCUSSION}

Habitat quality conditions have crucial effect on presence and size of animal populations (Griffen \& Drake 2008, Örvössy et al. 2013, 2014). To our knowledge, no relationship was found between submerse vegetation and body morphology of any water insect species yet. In our study, sampling sites of the water scorpion $N$. cinerea aggregated in two clearly distinct groups. The most important divorcing factor of the sampling sites was the submerse plant density. In addition, some morphological differences of the N. cinerea individuals found in the two contrasting habitat types were detected. These results show that $N$. cinerea morphology seems to be influenced by submerse plant density of the habitat.

Long-distance moving activity of the $N$. cinerea is poorly known. It was generally accepted that $N$. cinerea does not have flying ability (HаміLton 1931, Soós 1963, Southwood \& Leston 1959). In contrast, Lempert (1997) observed flying individuals from one pond in Germany two subsequent years. That is 
why it was supposed in a conservative manner in our study that adult individuals did not move away longer (i.e. one or more kilometre) distance from their sampling place. Consequently, habitat characteristic and adult morphology may be interrelated and it is highly likely that movement of individuals among the sampling sites did not influence the results.

Morphological differences within a single insect species across continental scale were detected several times. It is generally accepted that latitudinal differences may have diverse morphological changes in terrestrial insect species (Hodkinson 2005). However, Shelomi (2012) found that although there are several examples for the Bergmann's rule in the insect species, this hypothesis should be validated more carefully in the future. In the case of aquatic insects fewer examples are available. JoHAnsson (2003) found that the relationship between body size of the damsefly Enallagma cyathigerum (Charpentier, 1840) (Odonata: Coenagrionidae) and latitude is U-shaped in an European scale. Morphology of the midge Chironomus calligraphus Goeldi, 1905 (Diptera: Chironomidae) larva (SpIEs et al. 2002) and the water boatmen Sigara potamius Young, 1962 (Heteroptera: Corixidae) (Buckley \& Young 2008) show minor regional differences. However, decrease in body size from northern to southern Italy was found in the case of both water bug species $N$. cinerea ( $\mathrm{TA}_{\mathrm{A}}-$ MANINI 1973) and Sigara nigrolineata (Fieber, 1848) (Heteroptera: Corixidae) (TAMANini 1981).

We did not find such differences. It is most probably because our sampling scale was smaller than those in the mentioned studies.

It was found in this study that $N$. cinerea individuals (both sexes) sampled from the habitat type where submerse plant density was low, have longer hind leg claws. In the case of males, the length of the tarsus and claws of the middle leg proved to be also longer. According to these findings, it is likely that the morphology of the walking legs is important in the habitat adaptation of $N$. cinerea. Such adaptation of the claw was already proven in the case of the cricket Acheta domesticus L., 1758 (Orthoptera: Gryllidae) (Lepore et al. 2013) and the water mayfly Epeorus assimilis Eaton, 1855 (Ephemeroptera: Heltageniidae) (Ditsche-Kuru et al. 2012). Shorter claws on the middle leg of the corixid Arctocorisa carinata proved to be advantageous for grasping to the bottom (JANsson \& PAJUnen 1978). Dissimilar function may have the claws on middle and hind legs of $N$. cinerea in comparison to corixids, because $N$. cinerea has walking and not grasping meso- and meta-thoracic legs. However, the clear function of these claws has to be discovered.

Body shape is an essential phenotypic character of the aquatic Ephemeroptera, Plecoptera, Trichoptera and Odonata larvae, but data are limited for many taxa (ORLOFSKe \& BAIRd 2014). No such information is available for $N$. cinerea. In our study, individuals sampled from habitat where the submerse vegetation was more or less lacking have greater body parameters in all cases, 
if significant difference occurred. Moreover, broader male pronotum, greater body length from the end of the scutellum to the anal siphon and the distance between the eyes shows that females sampled from habitat type B were more robust than those found in habitat type A. It is hypothesized that robustness reflects to greater musculature which may be advantageous in vegetation poor habitat (habitat type B) where the animals are exposed to water flow and probably forced to move more often. This effect may be important, because $N$. cinerea is a sit-and-way predator, which is moving rarely.

The first pair of the $N$. cinerea legs is specialized catching of the prey (Hamilton 1931). Tactile and chemical stimuli triggered by the pray play primer importance in feeding (Abraham 1943, Greven \& Brenner 2007). Foreleg morphology in Belostomatidae, a relative taxon to Nepidae (ОнвA et al. 2008), as well as in the case of N. cinerea (Gorb 1995) is relevant to the manner of catching prey. We did not find any significant differences in first leg morphology. Therefore, it is concluded that feeding habit and strategy was not notably different between $N$. cinerea populations according to their habitat type.

Sexual size dimorphism is generally distributed phenomenon in animals. The association between fitness and phenotype differs according to the sex, but detailed understanding the mechanisms is poorly understood (STILLWELL et al. 2010). Female larvae of the chironomid Telmatogeton torrenticola (Terry, 1913) (Diptera: Chironomidae) were more than twice as large as males and this difference was influenced considerably by the habitat (BEnBow 2008). No such effect was found in our study in spite of the fact that body length of the males and females differed significantly.

Results of this study confirm the importance of the habitat effect, especially submerse plant density, on N. cinerea morphology. Body shape and leg morphology showed relationship with habitat characteristics. This may be a sign of phenotypic plasticity, which may one of the explanations of widespread distribution of $N$. cinerea in diverse habitats.

Acknowledgements - The authors are grateful to Judit Bakonyi for drawing Figure 1. We thank the reviewers and Dr. F. Cianferoni for their helpful and constructive comments.

\section{REFERENCES}

Авraнaм, G. R. (1943) Über die Beteiligung der Vorderbeine an der Chemorezeption bei einigen Wasserwanzen. Zeitschrift für vergleichende Physiologie 30(1): 321-342. http:// dx.doi.org/10.1007/BF00338592

Agrawal, A. A. (2001) Phenotypic plasticity in the interactions and evolution of species. Science 294: 321-326. http://dx.doi.org/10.1126/science.1060701 
Benbow, M. E. (2008) Role of larval sexual dimorphism, biased sex ratios, and habitat on the energetics of a tropical chironomid. Environmental Entomology 37(5): 1162-1173. http://dx.doi.org/10.1093/ee/37.5.1162

Buckley, T. R. \& Young, E. C. (2008) A revision of the taxonomic status of Sigara potamius and S. limnochares (Hemiptera: Corixidae), water boatmen of braided rivers in New Zealand. New Zealand Entomologist 31(1): 47-57. http://dx.doi.org/10.1093/ee/37.5.1162

Carbonell, J. A., Cánovas, C. G., Collados, D. B., Ródenas, P. A., García, J. V. \& Sánchez, A. M. (2011) Ecological factors determining the distribution and assemblages of the aquatic Hemiptera (Gerromorpha \& Nepomorpha) in the Segura River basin (Spain). Limnetica 30(1): 59-70.

Coulianos, C.-C., ØKLAND, J. \& ØKLAND, K. A. (2008) Norwegian water bugs. Distribution and ecology (Hemiptera-Heteroptera: Gerromorpha and Nepomorpha). Norwegian Journal of Entomology 55: 179-222.

Dahl, J. \& Peckarsky B. L. (2002) Induced morphological defenses in the wild: predator effects on a mayfly, Drunella coloradensis. Ecology 83: 1620-1634. http://dx.doi. org/10.1890/0012-9658(2002)083\%5B1620:IMDITW\%5D2.0.CO;2

Ditsche-Kuru, P., Barthlott, W. \& Koop, J. H. (2012) At which surface roughness do claws cling? Investigations with larvae of the running water mayfly Epeorus assimilis (Heptageniidae, Ephemeroptera). Zoology 115(6): 379-388. http://dx.doi.org/10.1016/j. zool.2011.11.003

Franken, R. J., Gardeniers, J. J., Beijer, J. A. \& Peeters, E. T. H. M. (2008) Variation in stonefly (Nemoura cinerea Retzius) growth and development in response to hydraulic and substrate conditions. Journal of the North American Benthological Society 27(1): 176-185. http://dx.doi.org/10.1899/07-066.1

García-Avilés, J., Puig, M. A. \& Soler, A. G. (1996) Distribution and associations of the aquatic Heteroptera of the Balearic Islands (Spain). Hydrobiologia 324(3): 209-217. http://dx.doi.org/10.1007/BF00016393

Gorb, S. N. (1995) Design of the predatory legs of water bugs (Hemiptera: Nepidae, Naucoridae, Notonectidae, Gerridae). Journal of Morphology 223(3): 289-302. http://dx.doi. org/10.1002/jmor.1052230306

Greven, H. \& Brenner, M. (2007) Sensillen auf den Fangbeinen von Nepa cinerea (Heteroptera) und Anmerkungen zum Beutefang. Entomologie Heute 19: 115-127.

Griffen, B. D. \& Drake, J. M. (2008) Effects of habitat quality and size on extinction in experimental populations. Proceedings of the Royal Society B: Biological Sciences 275(1648): 2251-2256. http://dx.doi.org/10.1098/rspb.2008.0518

Hamilton, M. A. (1931) The Morphology of the Water Scorpion. Nepa cinerea Linn. (Rhynchota. Heteroptera.). Proceedings of the Zoological Society of London 101: 1067-1136. http://dx.doi.org/10.1111/j.1096-3642.1931.tb01054.x

Hodkinson, I. D. (2005) Terrestrial insects along elevation gradients: species and community responses to altitude. Biological Reviews 80(3): 489-513. http://dx.doi.org/10.1017/ S1464793105006767

Hufnagel, L., BAKonyi, G. \& VÁsáRhelyi, T. (1999) New approach for habitat characterization based on species lists of aquatic and semiaquatic bugs. Environmental Monitoring and Assessment 58(3): 305-316. http://dx.doi.org/10.1023/A:1006047130545

Jansson, A. \& Pajunen, V. I. (1978) Morphometric comparison of geographically isolated populations of Arctocorisa carinata (C. Sahlberg) (Heteroptera, Corixidae). Annales Zoologici Fennici 15: 132-142.

Johansson, F. (2003) Latitudinal shifts in body size of Enallagma cyathigerum (Odonata). Journal of Biogeography 30(1): 29-34. http://dx.doi.org/10.1046/j.1365-2699.2003.00796.x 
KlingenberG, C. P. (2011) MorphoJ: an integrated software package for geometric morphometrics. Molecular Ecology Resources 11: 353-357. http://dx.doi.org/10.1111/j.17550998.2010.02924.x

Lempert, J. (1997) On the emigration of Nepa cinerea L. Drosera 97: 41-44.

Lepore, E., Chappoz, C., Monetta, D. C. \& Pugno, N. (2013) Surface roughness, claw size and leg elasticity influences on the jumping of Acheta domesticus crickets. Composite Structures 100: 609-616. http://dx.doi.org/10.1016/j.compstruct.2012.09.045

Lock, K., Adriaens, T., Van De Meutter, F. \& Goethals, P. (2013) Effect of water quality on waterbugs (Hemiptera: Gerromorpha \& Nepomorpha) in Flanders (Belgium): results from a large-scale field survey. Annales de Limnologie-International Journal of Limnology 49(2): 121-128. http://dx.doi.org/10.1051/limn/2013047

Malmqvist, B., Zhang, Y. \& Adler, P. H. (1999) Diversity, distribution and larval habitats of North Swedish blackflies (Diptera: Simuliidae). Freshwater Biology 42(2): 301-314. http://dx.doi.org/10.1046/j.1365-2427.1999.444497.x

Nosek, J. N., VÁsárhelyi, T., BAKonyi, G. \& Oertel, N. (2007) Spatial pattern of water bugs (Nepomorpha, Gerromorpha) at different scales in the Szigetköz (Hungary). Biologia 62(3): 345-350. http://dx.doi.org/10.2478/s11756-007-0057-9

Ohва, S. Y., Tatsuta, H. \& Nakasuji, F. (2008) Variation in the geometry of foreleg claws in sympatric giant water bug species: an adaptive trait for catching prey? Entomologia Experimentalis et Applicata 129(2): 223-227. http://dx.doi.org/10.1111/j.15707458.2008.00772.x

Orlofske, J. M. \& BAird, D. J. (2014) A geometric morphometric approach to establish body-shape trait criteria for aquatic insects. Freshwater Science 33(3): 978-994. http:// dx.doi.org/10.1086/676912

Örvössy, N., Kőrösi, Á., Batáry, P., Vozár, Á. \& Peregovits, L. (2013) Potential metapopulation structure and the effects of habitat quality on population size of the endangered False Ringlet butterfly. Journal of Insect Conservation 17(3): 537-547. http:// dx.doi.org/10.1007/s10841-012-9538-4

Örvössy, N., Kốrösi, Á., Batáry, P., VozÁr, Á. \& Peregovits, L. (2014) Habitat requirements of the protected Southern Feston (Zerynthia polyxena); adult, egg and larval distribution in a highly degraded habitat complex. Acta Zoologica Academiae Scientiarum Hungaricae 60(4): 371-387.

Polmemus, J. T. (1995) Family Nepidae Latreille, 1802 - water scorpions, water stick insects. Pp. 14-18. In: Aukema, B. \& Rieger, C. (eds): Catalogue of the Heteroptera of the Palaearctic Region. Volume 1. Enicocephalomorpha, Dispocoromorpha, Nepomorpha, Gerromorpha and Leptopodomorpha. The Netherlands Entomological Society, Wageningen.

R Core Team (2013) R: A language and environment for statistical computing. R Foundation for Statistical Computing, Vienna, Austria. ISBN 3-900051-07-0, http://www.R-project.org/

Rohlf, F. J. (2013) TPSDig 2.17. Department of Ecology and Evolution, State University of New York at Stony Brook, New York.

Shelomi, M. (2012) Where are we now? Bergmann's rule sensu lato in insects. The American Naturalist 180(4): 511-519. http://dx.doi.org/10.1086/667595

Soós, Á. (1963) Poloskák VIII. - Heteroptera VIII. Akadémiai Kiadó, Budapest. 48 pp. [in Hungarian]

Southwood, T. R. E. \& Leston, D. (1959) Land and water bugs of the British Isles. Frederick Warne Ltd, London, 436 pp.

Spies, M., Sublette, J. E., Sublette, M. F., Wülker, W. F., Martin, J., Hille, A., Miller, M. A. \& WitT, K. (2002) Pan-American Chironomus calligraphus Goeldi, 1905 (Diptera, 
Chironomidae): species or complex? Evidence from external morphology, karyology and DNA sequencing. Aquatic Insects 24(2): 91-113. http://dx.doi.org/10.1076/ aqin.24.2.91.4900

Statzner, B. \& Holm, T. F. (1982) Morphological adaptations of benthic invertebrates to stream flow - an old question studied by means of a new technique (laser doppler anemometry). Oecologia 53: 290-292. http://dx.doi.org/10.1007/BF00389001

Stillwell, R. C., Blanckenhorn, W. U., Teder, T., Davidowitz, G. \& Fox, C. W. (2010) Sex differences in phenotypic plasticity affect variation in sexual size dimorphism in insects: from physiology to evolution. Annual Review of Entomology 55: 227-245. http:// dx.doi.org/10.1146/annurev-ento-112408-085500

Tamanini, L. (1973) Priorità e sinonimia di Nepa cínerea Linneo e Nepa rubra Linneo. Regione tipica e valore delle razze europee di Nepa cinerea Linneo, 1758 (Hemiptera Heteroptera, Nepidae). Studi Trentini di Scienze Naturali, Sez. B 1(2): 222-259.

TAmanini, L. (1979) Eterotteri acquatici (Heteroptera: Gerromorpha, Nepomorpha). Guide per il Riconoscimento delle Specie Animali delle Acque Interne Italiane. CNR, AQ/1/43 6: $1-106$.

Tamanini, L. (1981) Gli Eterotteri della Basilicata e della Calabria. Italia meridionale (Hemiptera Heteroptera). Memorie del Museo civico di Storia naturale di Verona (II serie), Sezione Scienze della Vita (A: Biologica) 3: 1-164.

Van de Meutter, F., Stoks, R. \& De Meester, L. (2005) The effect of turbidity state and microhabitat on macroinvertebrate assemblages: a pilot study of six shallow lakes. Hydrobiologia 542: 379-390. http://dx.doi.org/10.1007/s10750-005-4941-4

Via, S., Gomulkiewicz, R., De Jong, G., Scheiner, S. M., Schlichting, C. D. \& Van TienDEREN, P. H. (1995) Adaptive phenotypic plasticity: consensus and controversy. Trends in Ecology and Evolution 10: 212-217. http://dx.doi.org/10.1016/S0169-5347(00)89061-8

West-Eberhard, M. J. (1989) Phenotypic plasticity and the origins of diversity. Annual Review of Ecology and Systematics 20: 249-278. http://dx.doi.org/10.1146/annurev. es.20.110189.001341

Zhang, Y. \& Malmovist, B. (1997) Phenotypic plasticity in a suspension-feeding insect, Simulium lundstromi (Diptera: Simuliidae), in response to current velocity. Oikos 78(3): 503-510. http://dx.doi.org/10.2307/3545611

Received August 3, 2015, accepted November 28, 2015, published October 6, 2016 